\title{
Malathion-resistant Tribolium castaneum has enhanced response to oxidative stress, immunity, and fitness.
}

\author{
Abdur Rauf ${ }^{\mathrm{a}}$ and Richard M Wilkins ${ }^{\mathrm{b} *}$
}

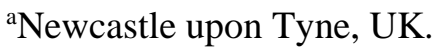

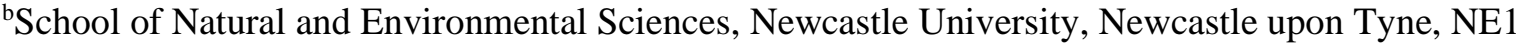
7RU, UK

*corresponding author, Orcid 0000-0001-8984-4960.

E-mail address: Richard.Wilkins@ncl.ac.uk, richardmjw@gmail.com

\begin{abstract}
Many cases of insecticide resistance in insect pests give resulting no-cost strains that retain the resistance genes even in the absence of the toxic stressor. Malathion has been widely used against the red flour beetle, Tribolium castaneum Herbst. in stored products although no longer used. Malathion specific resistance in this pest has provided resistance that is long lasting and widely distributed. To understand this resistance a malathion resistant strain was challenged with a range of stressors including starvation, hyperoxia, malathion and a pathogen and the antioxidant responses and some lifecycle parameters were determined.
\end{abstract}

Adult life span of malathion-specific resistant strain of $T$. castaneum was significantly shorter than the susceptible. Starvation and/or high oxygen reduced adult life span of both strains. Starving with and without $100 \%$ oxygen gave longer lifespan for the resistant strain, but for oxygen alone there was no difference. Under oxygen the proportional survival of the resistant strain to the adult stage was significantly higher, for both larvae and pupae, than the susceptible. The resistant strain when stressed with malathion and/or oxygen significantly increased catalase activity, but the susceptible did not. The resistant strain stressed with Paranosema whitei infection had significantly higher survival compared to the susceptible, and with almost no mortality.

The malathion resistant strain of $T$. castaneum showed greater vigour than the susceptible in most oxidative stress situations and especially where stressors were combined. The induction of the antioxidant enzyme catalase could have helped the resistant strain to withstand oxidative stresses, including insecticidal and importantly those from pathogens. These adaptations, in the absence of insecticide, seem to support the increased immunity of host insects to pathogens seen in other insect 
species, such as mosquitoes. By increasing the responses to a range of stressors the resistant strain could be considered as having enhanced fitness.

Key words Tribolium castaneum, malathion-resistance, hyperoxia, Paranosema whitei, catalase, oxidative stress.

\section{Introduction}

Malathion resistance in the red flour beetle, Tribolium castaneum (Herbst), is a worldwide problem and as it is very stable it became widespread in natural populations (Dyte and Blackman, 1970), with the first case of malathion-specific resistance in T. castaneum reported in Nigeria (Parkin et al. 1962). In the absence of insecticide, this resistance does not reduce fitness, being the genetic contribution to future generations. Evidence for malathion specific resistance shows, that in the absence of treatment, there is no fitness difference between resistant and susceptible strains or the resistant strain has a fitness advantage (Beeman and Nanis 1986; McKenzie and Farrell 1993; White and Bell 1995; Haubruge and Arnaud 2001; Arnaud et al. 2002; Arnaud and Haubruge 2002; Bughio and Wilkins 2004; Arnaud et al. 2005; Okoye et al. 2007; Kliot and Ghannin 2012; Grigoraki et al, 2017). A malathion-specific resistant strain showed an $8-23 \%$ increase in biotic potential (fecundity and developmental time) relative to the susceptible strain (Haubruge and Arnaud 2001). Malathionspecific carboxyesterases (MCE) have been implicated in a range of insect species. These include several strains of mosquitoes (Whyard and Walker, 1994; Whyard et al. 1995), moths (Beeman and Schmidt 1982), pteromalid parasitoids (Baker et al. 1998), beetles (Price 1984, Spencer et al. 1998, Haubruge et al. 2002) and fruit flies (Wang et al, 2017). The persistence of the malathion resistance in these species/strains is often not known.

However, most studies have shown fitness costs associated with insecticide resistance (McKenzie and Farrell 1993; Kliot and Ghannin 2012; Cao et al., 2014; Guillem-Amat et al., 2020), and specifically for T. castaneum in the case of phosphine resistance (Oppert et al., 2015; Nayak et al., 2020). In fact, in $60 \%$ of fitness reports there was a cost for resistance but less commonly for organochlorines (Freeman et al, 2021).

Exposure to radiation, ultraviolet light, and some chemicals results in the production of reactive oxygen species (ROS) such as hydrogen peroxide and superoxide anion radical, usually via the mitochondria of cells (Towarnicki et al., 2020). In general, ROS are harmful to living organisms because ROS can cause oxidative damage to proteins, nucleic acids and lipids (Gladyshev 2014; Sies, 2015). In this context, ROS has been recognized to be related to animal aging and life span (Parkes et 
al., 1999; Otali, 2014; Zhang et al., 2017). ROS stimulates signal transduction (Schieber and Chandel, 2014) and mediates various responses such as cell growth and apoptosis (Suzuki et al. 1997; Speakman et al, 2015). On the other hand, ROS plays a helpful role in the innate immunity system of an insect (Futo et al, 2016; Khan et al, 2017). Hydrogen peroxide may have a role in effecting hormesis (Ludovico and Burhans, 2014). Living organisms thus require a regulatory system for ROS. Antioxidant enzymes scavenge ROS. Catalase $\left(\mathrm{H}_{2} \mathrm{O}_{2}\right.$ oxidoreductase; EC 1.11.1.6, CAT) plays an essential role and catalyses the degradation of $\mathrm{H}_{2} \mathrm{O}_{2}$ to water and oxygen (Yamamoto et al. 2005; Sies, 2017).

Other antioxidant enzymes such as superoxide dismutase, glutathione transferase, and glutathione reductase have been characterized in insects (Felton and Summers, 1995). Oxidative stress results from an imbalance of oxidants and antioxidants, either a surfeit of oxidants and/or a deficit of antioxidants (Gladyshev 2014). The antioxidant enzymes superoxide dismutase (SOD), catalase (CAT), and glutathione peroxidase (GPx) are the main enzymatic defences and act in concert with a panoply of non-enzymatic antioxidants (Kodrík et al, 2015). The elaboration of antioxidant defences is presumed to have played a critical role in the evolution of oxygen-respiring organisms, especially terrestrial arthropods. Catalase, by virtue of its ability to break down $\mathrm{H}_{2} \mathrm{O}_{2}$ into $\mathrm{H}_{2} \mathrm{O}$ and $\mathrm{O}_{2}$, plays an important role in mitigating oxidative damage, since $\mathrm{H}_{2} \mathrm{O}_{2}$ is a ready source for hydroxyl radical $(\cdot \mathrm{OH})$ formation via Fenton chemistry. Together with superoxide dismutase (SOD), catalase forms a major antioxidative axis, and, as such, can impact directly on cellular redox status (Klichko et al., 2004; Sies, 2017).

GSTs play a vital role in protecting tissues against oxidative damage and oxidative stress. Elevated GSTs in a resistant strain attenuated the pyrethroid-induced lipid peroxidation and reduced mortality, whereas their inhibition eliminated their protective role (Vontas et al., 2001).

Stressors which increase ROS in insects can include starvation, elevated oxygen levels, toxins (e.g. malathion) and parasites/pathogens. We will consider the effects of these on a susceptible and a malathion-resistant strain of $T$. castaneum. Various classes of pesticides induce reactive oxygen species and oxidative tissue damage which may contribute to the toxicity of these xenobiotics (Abdollahi et al., 2004). Reactive oxygen species may serve as common mediators of programmed cell death (apoptosis) in response to many toxicants and pathological conditions (Bagchi et al., 1995). In the case of Drosophila melanogaster, treatment with malathion increased stress tolerance and life span (i.e. fitness) (Bonilla et al., 2002). Low doses of imidacloprid bind to the insect brain, causing rapid release of $\mathrm{Ca}^{+}$and ROS (Martelli et al., 2020). The insect is weakened and less able to tolerate environmental stresses. In fact, catalase in this species decreases with age and plays a role in redox signalling (Lennicke and Cochemé, 2020). 
Oxidative damage in insects is thought to be high because they usually have no oxygen binding proteins in their blood so oxygen is carried directly to their cells via the tracheolar network which exposes them to four-to-five-fold higher concentrations of oxygen than in animals with blood haemoglobin. Free radicals impair metabolism and necessitate protection and repair especially during starvation, poor diet, desiccation and rehydration. Raising houseflies in an atmosphere of $100 \%$ oxygen reduced their mean and maximum life span and it increased their levels of protein carbonyls in whole body extracts (Sohal et al., 1993) and in the mitochondria (Towarnicki et al., 2020). Cells exposed to low oxygen levels (hypoxia) activate the transcription factor hypoxia-inducible factor 1 (HIF-1) as an adaptive response. Cells exposed to hypoxia do not undergo senescence or cell death and do not diminish ATP levels. By contrast, cells exposed to high oxygen levels (hyperoxia) undergo senescence and cell death and decrease their ATP levels, yet do not activate HIF-1 (Harrison et al., 2006). Despite these divergent responses with respect to senescence, cell death, metabolism, and gene expression, the signalling events in both systems are mediated by the generation of mitochondrialderived reactive oxygen species (ROS) (Chandel and Budinger, 2007). High mortality of $T$. castaneum was found when exposed to $90 \%$ oxygen (Calderon, 1991; Wang et al., 2018). Adult $T$. castaneum under hypoxia depressed mitochondrial function but following reoxygenation increased their antioxidant activity (Wang et al., 2018). Long term selection of Drosophila melanogaster with $90 \%$ oxygen generated a resistant strain that were larger and had increased body weight by $20 \%$ (Zhao et al., 2010).

In view of the increased fitness of the highly malathion-specific resistant strain of $T$. castaneum characterised here, and the universal replacement of previous susceptible populations by similar malathion resistant strains (Attia et al., 2020), it was relevant to determine its responses to additional oxidative stresses. Previous work had shown enhanced fitness when this strain was stressed on a less suitable grain (rice) for food (Bughio and Wilkins, 2004). Further studies showed enhanced gut capability in terms of tolerance to protease inhibition (Bughio and Wilkins, 2021). The role of catalase, the crucial antioxidant enzyme (Sies, 2017), was to be explored, using the highly resistant strain. Although malathion is little used for T. castaneum management, the characteristics of resistant strains, which are widespread in stored products (Anusree et al, 2019), are important in developing sustainable strategies. Understanding the redox relationship in the resistant strain is useful when considering the use of phosphine, other insecticides/natural products or natural enemies in any extant population of this pest (Nayak et al., 2019). Thus, the objectives were to compare the responses of an insecticide resistant strain, with no-cost fitness traits and which is widespread, to stressors such as hyperoxia, starvation, pathogen and malathion, and combinations (with a standard susceptible strain). Responses included longevity, survival, immunity and catalase induction, and their contributions to fitness. 
The choice of parasite stressor was Paranosema whitei (Weiser) (species previously known as Nosema whitei Weiser has now been replaced (Sokolova et al., 2005)). This is an important parasite for Tribolium and a potential biocontrol agent, and is an obligate, intra-cellular microsporidian (protozoan). The pathogen has been almost always lethal in the late larval and pupal stages of the host T. castaneum so that only a few individuals manage to enclose to adult (Milner, 2006). Transmission of $P$. white i is horizontal and occurs after host death when the infected larva, pupa or adult dies, and is destroyed either when the host medium is mechanically treated (as in stored products) or the carcass is cannibalized.

\section{Materials and methods}

\subsection{Insect strains red flour beetle T. castaneum}

Two strains of $T$. castaneum, PH-1 and FSS-II, were maintained at the School of NES, Newcastle University, UK. The malathion-specific resistant Ph-1 strain (Rauf and Wilkins, 2002; Haubruge et al, 2002) was previously received from Natural Resources Institute, UK and the FSS-II strain of $T$. castaneum was obtained from Central Science Laboratory, York, UK. The susceptible strain of T. castaneum, FSS-II, was described by Lagisz et al. (2010). Wholemeal wheat flour supplemented with $5 \%$ brewer's yeast at $29 \pm 1^{\circ} \mathrm{C}$ and $65 \pm 5 \% \mathrm{RH}$, in the dark, was used as the culture medium. The natural resistant strain was further selected with malathion by topical application of technical grade malathion to the adults to give around $90 \%$ mortality and the survivors were used to produce the next generation. This treatment was repeated for every third generation. After five such sequential selections, the initial $\mathrm{LD}_{50}$ value of $6.4 \mu \mathrm{g} /$ beetle increased to $135 \mu \mathrm{g} /$ beetle $(\mathrm{Ph}-5)$ and after 10 selection cycles the $\mathrm{LD}_{50}$ had risen to $162 \mu \mathrm{g} /$ beetle $(\mathrm{Ph}-10)$. The enhanced strains were utilized in conjunction with the reference susceptible FSS-II strain. These field derived strains were used to ensure stable and effective resistance levels and although they are not directly geneticallyrelated they provide realistic subjects. Responses to sequential malathion selection are given in Table 1. Further characterisation of these strains with respect to other insecticides and synergists are provided in Supplementary Materials.

Table $1 . \mathrm{LD}_{50}$ values (and 95\% confidence intervals) and resistance factors (RF) of susceptible and resistant strains of $T$. castaneum

\begin{tabular}{llll}
\hline Strain $^{\mathrm{a}}$ & $\mathrm{LD}_{50} \mu \mathrm{g} /$ insect & Slope \pm SE & RF \\
\hline FSS-II & $0.027(0.02-0.03)$ & $3.92 \pm 0.51$ & - \\
\hline
\end{tabular}




\begin{tabular}{llll}
\hline Ph-1 & $6.4(5-8)$ & $2.76 \pm 0.32$ & 237 \\
\hline Ph-2 & $75(65-94)$ & $4.81 \pm 0.61$ & 1562 \\
\hline Ph-5 & $135(112-170)$ & $4.84 \pm 0.55$ & 2812 \\
\hline Ph-10 & $162(142-191)$ & $5.15 \pm 0.57$ & 3375
\end{tabular}

\footnotetext{
${ }^{a} \mathrm{Ph}$ strain, number of malathion selection cycles (every 3 generations) starting with Ph-1.
}

\subsection{Application of oxidative stress to $T$. castaneum using oxygen}

\subsubsection{Adult lifespan}

Pure oxygen atmosphere conditions were maintained in a 30x30x30 cm clear plastic chamber, kept within an incubator, by passing a continuous gentle stream of humidified filtered $100 \%$ oxygen (from a gas cylinder BOC) through the chamber with the outlet bubbled through water outside the chamber. A $29 \pm 1^{\circ} \mathrm{C}$ temperature and $65 \pm 5 \%$ relative humidity was maintained in the chamber. To study the effect of pure oxygen on the adult stage of the strains of $T$. castaneum, 2-5-day-old beetles (20) of each strain were kept in $30 \mathrm{ml}$ glass vials (5 in total) with culture medium (1 g) in each, within the chamber. The food medium was changed every 15 days. In the control, filtered humidified normal air (supplied from a compressed air cylinder BOC) was used instead of pure oxygen. The effect on the adult mortality was observed with and without providing food to the beetles. Under fed conditions, mortality was noted every two days under oxygen and every fortnight in the air/control; while, where the beetles were kept starved, mortality was observed every day in both oxygen stressed and control conditions. The data obtained were analysed using survival curves drawn using Graphpad Prism V9 to obtain number of days for median survival of the population and curve comparison under the various stress conditions.

\subsubsection{Short-term stress to determine catalase activity}

Adults of both strains were stressed with malathion; 100 adult beetles were treated topically (prior to placing in the chamber) with a technical grade malathion solution in acetone at $\mathrm{LD}_{50}$ level (adults placed in $1 \mathrm{~g}$ culture medium, 3 replicates). Mortality was noted after $24 \mathrm{~h}$ with, and without, pure oxygen. The survivors were killed by freezing and kept at $-20^{\circ} \mathrm{C}$ to determine catalase activity.

\subsubsection{Survival of immature stages}

The survival of larval and pupal stages of the strains of $T$. castaneum was noted by counting the number of adults that emerged after 15 days in the case of larvae and 10 days for the pupae. Ten last instar larvae or newly pupated pupae were transferred to vials containing culture medium $(1 \mathrm{~g})$ and kept in the chambers with air or $100 \%$ oxygen under standard conditions. For each life stage five replicates were used. 


\subsection{Determination of catalase activity}

\subsubsection{Homogenisation of insects}

Crude enzyme extracts of $T$. castaneum were prepared by homogenising $40 \mathrm{mg}$ of adult beetles in $1.5 \mathrm{ml}$ of ice cold $0.05 \mathrm{M}$ phosphate buffer $\mathrm{pH}$ 7. The homogenates were centrifuged and the supernatants were used as the enzyme source.

\subsubsection{Assay of catalase activity}

Catalase activity was determined by using a modification of the spectrophotometric method of Durusoy et al. (1995). Reactions, at $30^{\circ} \mathrm{C}$, were initiated by the addition of $50 \mu \mathrm{l}$ of the supernatant to $3 \mathrm{ml}$ of a substrate solution containing $0.05 \mathrm{M}$ sodium-potassium phosphate buffer, $\mathrm{pH}$ 7, and $\mathrm{H}_{2} \mathrm{O}_{2}$ at a final concentration of $20 \mathrm{mM}$. Catalase activity was measured as a decrease in $\mathrm{H}_{2} \mathrm{O}_{2}$ concentration. The decrease in absorbance at $230 \mathrm{~nm}$ was monitored for $1.5 \mathrm{~min}$ and was noted at every $0.5 \mathrm{~min}$. The consumption rate of $\mathrm{H}_{2} \mathrm{O}_{2}$ was calculated using a calibration curve of $\mathrm{H}_{2} \mathrm{O}_{2}$ in a concentration range from 2 to $50 \mathrm{mM}$. The initial activity was determined from the slope of the line ( $\triangle$ O.D. per min). The activity was expressed as micromole of $\mathrm{H}_{2} \mathrm{O}_{2}$ decomposed per min per milligram of protein. Protein concentration of the homogenates was determined by the method of Bradford (1976) using bovine serum albumin as a standard.

\subsection{Paranosema whitei infection of T. castaneum}

The malathion-specific resistant $\mathrm{Ph}-5$ and susceptible FSS-II strains of $T$. castaneum were used to test their susceptibility to Paranosema whitei, a microsporidian pathogen of this species. An infected stock of FSS-II strain was the inoculum (Khan and Selman, 1988). To prepare the infective material containing the pathogen spores, the host larvae killed by the disease were ground with a mortar and pestle. The dried crushed material was sieved through 100-mesh sieve and the powder was stored at room temperature to use for infection.

For each strain, ten $30 \mathrm{ml}$ glass vials were prepared, each containing wholemeal wheat flour $(10 \mathrm{~g})$ with $5 \%$ brewer's yeast. Twenty randomly selected same-age beetles of each strain, irrespective of gender, were put in each vial for egg laying and kept at $29 \pm 1^{\circ} \mathrm{C}$ and $65 \pm 5 \%$ relative humidity. After three days the beetles were removed by sieving. The above infective powder (30 mg), containing disease spores, was added and carefully mixed in each vial. The emergence of adult beetles was noted after 35 days.

\subsection{Statistical analysis}


The response data were analysed by probit/logit regression analysis using the computer programme POLO PC (Leora Software, Berkeley, CA, 1987). All other results were analysed with GraphPad Prism V9 for Windows (GraphPad Software San Diego, CA, USA) using two-way analysis of variance ANOVA, with posttest Bonferroni correction. Survival curves were drawn using Graphpad Prism V9 using the Kaplan-Meier survival fractions. Survival curves were compared using the Log-rank (Mantel-Cox) test with pre-planned pairs.

\section{Results}

\subsection{Exposure of adult insects to oxidative stress}

\subsubsection{Adult life span of the strains of $T$. castaneum with, and without, pure oxygen conditions}

The results show that adult life-spans of both strains were significantly reduced $(P<0.0001)$ under high oxygen conditions, as compared to the control in normal air (Table 2), irrespective of other stressors. However, starved insects were less impacted by oxygen exposure (medians reduced to 0.40 and 0.45 of control for the susceptible and resistant strains, respectively) than fed insects (median values reduced to 0.22 and 0.28 of control) with the resistant strain relatively less affected in both nutritional conditions (Table 2).

Table 2. Survival of the adults of strains of $T$. castaneum, comparing the responses to pure oxygen

\begin{tabular}{|c|c|c|c|c|c|c|}
\hline \multirow[t]{2}{*}{ Stress } & \multirow[t]{2}{*}{ Subjects } & \multirow{2}{*}{$\begin{array}{l}\text { Median } \\
\text { Days }\end{array}$} & \multirow{2}{*}{$\begin{array}{r}\text { Ratio }(95 \% \mathrm{CI}) \\
\mathrm{O}_{2} / \text { air control }\end{array}$} & \multicolumn{3}{|c|}{ Comparison of survival curves ${ }^{a}$} \\
\hline & & & & $\chi^{2}$ & $\mathrm{df}$ & $P$ \\
\hline \multirow[t]{4}{*}{$\mathrm{O}_{2}$} & $\mathrm{Ph}-10+\mathrm{fed}$ & 21 & $0.28(0.21-0.37)$ & 235.8 & 1 & $<0.0001$ \\
\hline & Ph-10+starved & 9 & $0.45(0.34-0.59)$ & 185.4 & 1 & $<0.0001$ \\
\hline & FSS-II+fed & 20 & $0.22(0.17-0.29)$ & 236.8 & 1 & $<0.0001$ \\
\hline & FSS-II+starved & 6 & $0.40(0.30-0.53)$ & 212.8 & 1 & $<0.0001$ \\
\hline \multirow[t]{4}{*}{$\begin{array}{l}\text { Air } \\
\text { (control) }\end{array}$} & $\begin{array}{l}\mathrm{Ph}-10+\text { fed (no } \\
\text { stress) }\end{array}$ & 75 & & & & \\
\hline & Ph-10+starved & 20 & & & & \\
\hline & $\begin{array}{l}\text { FSS-II+fed (no } \\
\text { stress) }\end{array}$ & 90 & & & & \\
\hline & FSS-II+starved & 15 & & & & \\
\hline
\end{tabular}

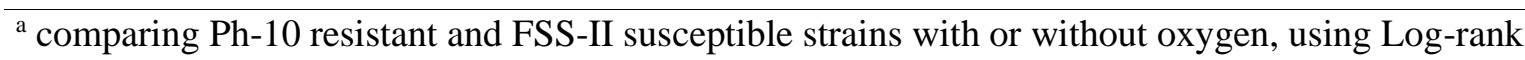
(Mantel-Cox) test.

In comparing the two strains, under fed conditions, the susceptible FSS-II strain survived significantly better $(P<0.0001)$ under normal air conditions as compared to the malathion-specific 
resistant strain of $T$. castaneum $\mathrm{Ph}-10$ (Fig 1 and Table 3 ). Under $100 \%$ oxygen this was reversed $(P<0.05)$, with the resistant strain living slightly longer (Fig 1 and Table 3 ) although the difference between the two was significant.
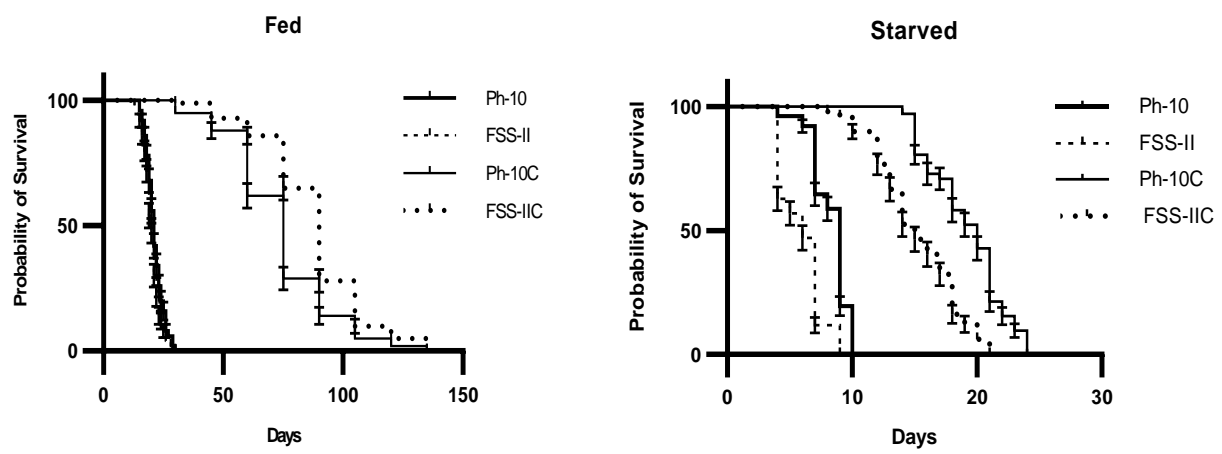

Fig. 1. Survival in adults of the strains of T. castaneum where wheat flour was used as food (Fed), and where no food was used (Starved) with $100 \%$ oxygen (Ph-10 and FSS-II) or control with air (Ph-10C and FSS-IIC). Ph-10 resistant, FSS-II susceptible. Error bars represent SEM.

$\mathrm{Fed}+\mathrm{O}_{2}$

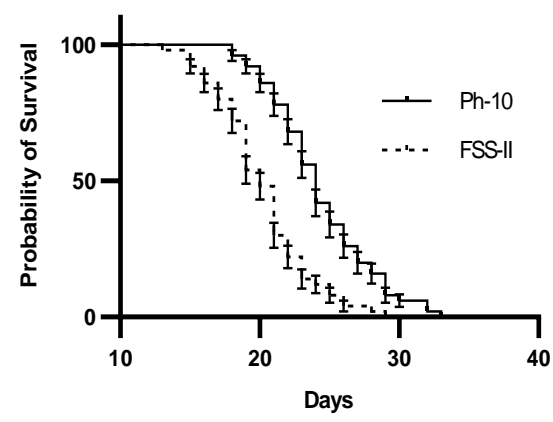

Fig 2. Survival in adults of the strains of T. castaneum where wheat flour was used as food with $100 \%$ oxygen. Ph-10 resistant, FSS-II susceptible. Error bars represent SEM. Ph-10 curve displaced +2.

The starved individuals of both strains lived significantly shorter $(\mathrm{P}<0.0001)$ lives than fed insects in both 100\% oxygen and the normal air control environment (Fig 1 and 2). Under starved conditions in normal air, the susceptible strain had shorter adult lives than the resistant. However, if pure oxygen is added as an extra stressor, the median survival for both is lowered substantially, but the resistant strain is less damaged.

Table 3. Summary of survival of the adults of strains of $T$. castaneum and comparison of survival curves 


\begin{tabular}{llrlrrc}
\hline Strain & Stress & Median & Ratio R/S & \multicolumn{3}{c}{ Comparison of survival curves $^{\text {a }}$} \\
& & Days & and (95\% CI) & \multicolumn{1}{c}{$\chi^{2}$} & df & \multicolumn{1}{c}{$P$} \\
\hline Ph-10 & air+fed (no stress) & 75 & $0.83(0.63-1.10)$ & 17.83 & 1 & $<0.0001$ \\
& air+starved & 9 & $0.60(0.46-0.79)$ & 185.4 & 1 & $<0.0001$ \\
& oxygen+fed & 21 & $1.05(0.80-1.38)$ & 4.96 & 1 & $0.026^{*}$ \\
& oxygen+starved & 9 & $1.50(1.14-1.98)$ & 75.94 & 1 & $<0.0001$ \\
FSS-II & air+fed (no stress) & 90 & & & & \\
& air+starved & 15 & & & & \\
& oxygen+fed & 20 & & & & \\
& oxygen+starved & 6 & & & & \\
* comparing Ph-10 resistant (R) with FSS-II susceptible (S), using Log-rank (Mantel-Cox) test. \\
* significantly different at <5\% P
\end{tabular}

\subsubsection{Survival of the late larval \& pupal stages to adulthood of the strains of $T$. castaneum maintained under air and pure oxygen conditions}

Both the larval and pupal stages of the susceptible strain of $T$. castaneum survived slightly better than the resistant in normal air conditions, but this difference was statistically non-significant (Fig 3). Comparing the two strains for late larval and pupal stages using Bonferroni correction gave, for air (control) conditions, larvae; t (32)=0.40, $\mathrm{P}>0.05(N S)$, pupae; $\mathrm{t}(32)=1.12, P>0.05(N S)$. Under oxygen stress conditions, the survival percent of the resistant $\mathrm{Ph}-10$ strain to the adult stage was significantly higher, both in larvae ( $\mathrm{t}(32)=4.45, P<0.001)$, and pupae ( $\mathrm{t}(32)=2.42, P<0.05)$, than the susceptible FSS-II strain (Fig 3). This enhanced survival of the no-cost malathion-resistant strain over the susceptible is consistent through the main stages of the life cycle.

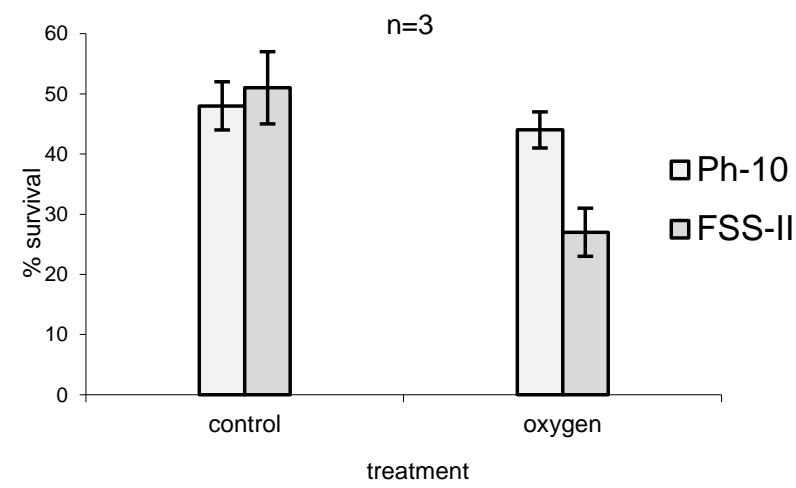

Fig. 3. The survival (\%) in late larval and pupal stages, to adult, in air (control) or $100 \%$ oxygen for the strains of $T$. castaneum. $\mathrm{n}=5$, number of replications, where 10 individuals for each replication were used. Ph-10 resistant, FSS-II susceptible. 


\subsubsection{Adult mortality in the two strains of $T$. castaneum treated with malathion in air or pure oxygen}

The mortality in the resistant $\mathrm{Ph}-10$ strain adults after topical treatment with malathion at $\mathrm{LD}_{50}$ level was marginally higher $(\mathrm{t}(8)=0.49$, non-significant $\mathrm{P}>0.05$, Bonferroni post-test) than the susceptible FSS-II strain where treated beetles were kept in normal air (Fig. 4). This slight variation can be explained by dosing errors. However, when combining the stressors (insecticide plus oxygen), the malathion-treated resistant strain showed significantly better survival $(\mathrm{t}(8)=2.83, \mathrm{P}<0.05)$ when kept under the pure oxygen conditions $(24 \mathrm{~h})$ after treatment with malathion at the same $\mathrm{LD}_{50}$ level.

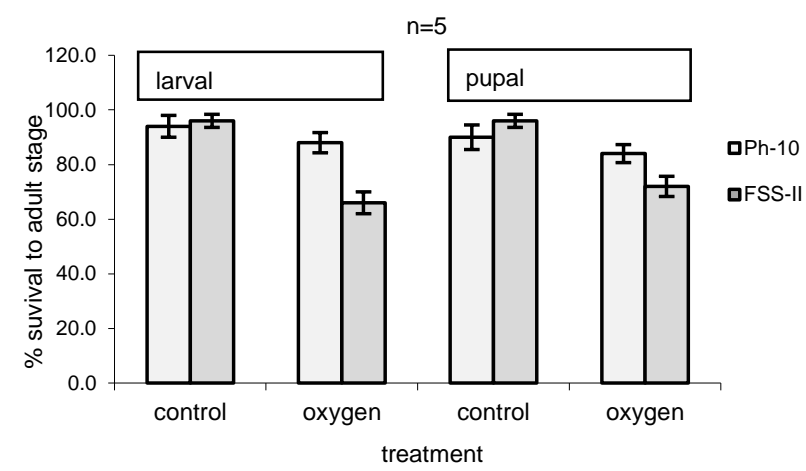

Fig. 4. Survival of adults of the strains of $T$. castaneum after treatment with malathion at $\mathrm{LD}_{50}$ level and without, and with, 24 hours $100 \%$ oxygen. $n=3$ number of replications, where 100 beetles for each replication were used.

\subsubsection{Catalase activity in the strains of $\boldsymbol{T}$. castaneum after malathion and pure oxygen treatment}

The catalase activities in non-insecticide-treated individuals of both strains were not significantly different from control following oxygen exposure (Fig. 5) (resistant Ph-10 t (16)= 1.77, $\mathrm{P}>0.05)$ and susceptible FSS-II $(\mathrm{t}(16)=0.55, \mathrm{P}>0.05)$. The mean catalase activity was not increased, in the malathion resistant strain after topical treatment with malathion $(\mathrm{t}(16)=0.92, \mathrm{P}>0.05$, NS), as compared to the untreated, where the beetles were kept under normal air conditions. For the susceptible strain there was also no significant change $(\mathrm{t}(16)=0.22, \mathrm{P}>0.05)$. But, the increase, in the enzyme activity, was significantly higher, than the control, for the resistant strain $(\mathrm{t}(16)=2.54$, $\mathrm{P}<0.05$ ), in the malathion treatment with oxygen for 24 hours. There was no significant change in the enzyme activities observed in the malathion susceptible strain $(\mathrm{t}(16)=0.14, \mathrm{P}>0.05)$, both after separate and combined effects of malathion and oxidative stress. Catalase activity was determined 24 $\mathrm{h}$ after acute treatment with malathion. 


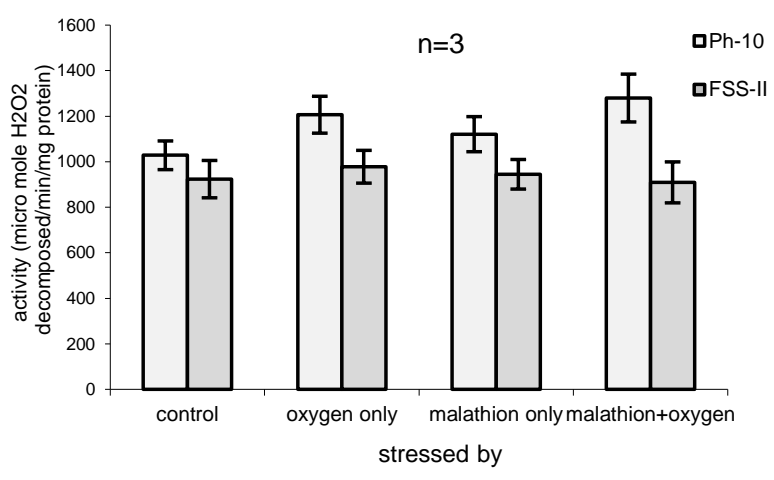

Fig. 5 Catalase activity in the strains of $T$. castaneum after stress with malathion at $\mathrm{LD}_{50}$ level and 24 hours $100 \%$ oxygen. $\mathrm{n}=3$ number of replications, where, $40 \mathrm{mg}$ of beetles for each replication were used.

\subsubsection{Paranosema whitei infection of T. castaneum}

Following infection of the early larval stage of the strains of $T$. castaneum with Paranosema whitei, we compared those beetles that grew to adulthood. The adult survival rate in the resistant (Ph5) strain was very significantly greater $(\mathrm{t}(36)=10.48, \mathrm{P}<0.001)$ than in the susceptible (FSS-II) strain $(\mathrm{t}(36)=0.27, \mathrm{P}>0.05)$ (Figure 6). There was little disease effect on the resistant strain $(\mathrm{P}>0.05)$ while the susceptible strain was nearly eliminated.

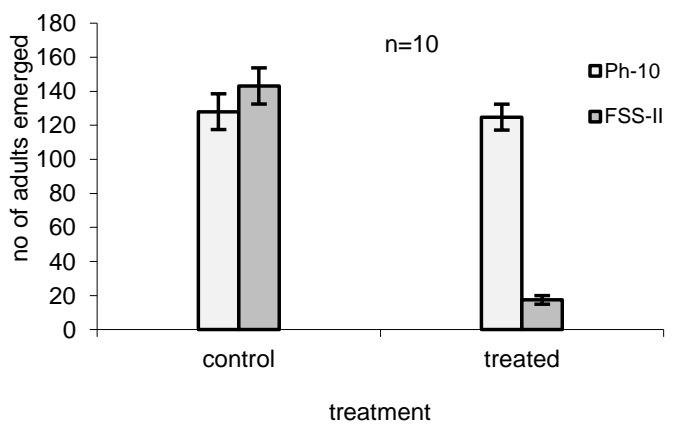

Fig. 6 Adult survival after treatment with Paranosema white in the strains of T. castaneum. $\mathrm{n}=10$ number of replications, where, 20 beetles for each replication were used. Errors bar represent SEM.

\section{Discussion}




\subsection{Lifespan and survival of the strains exposed to oxidative stressors}

Lifespan or longevity in adults of $T$. castaneum under laboratory conditions can extend from 60 to 200 days when strains developed under varying temperatures were compared (Hani Soliman and Lints, 1982). Depending on the strain, larval growth rates were negatively correlated with longevity of the adults. Strains originating from grain stores were compared for adult longevity and mean survival times were found to vary from 120 to 170 days (Kavallieratos et al, 2020) when fed on cracked barley. When fed on unsuitable rice grain the longevity was drastically shortened. All these insects were reared on wheat flour previously to the study (Kavallieratos et al, 2020). Generally, the expected adult lifespan under controlled conditions does depend on the strain (and conditions); however, there are no published results for insecticide-resistant strains of this species, particularly a no-cost resistant strain. The maximum lifespans of the strains in our study, which also had been in culture for many years, were 135 days (both strains) in fed conditions, in line with the previous studies. Under starved conditions, lifespans fell to 24 days (resistant Ph-10) and 21 days (susceptible FSS-II). These reductions are similar to non-resistant adults when fed on the unsuitable rice diet (Kavallieratos et al, 2020). Adult malathion-resistant Musca domestica when exposed to oxygen survived better than a susceptible strain and induced higher catalase levels (Rauf et al, 2008).

In our study we found that the adults of highly malathion-specific resistant strain of $T$. castaneum had relatively shorter lives (based on median values), in the normal air environment, than the susceptible and thus the resistant strain was less fit on the basis of adult life span. Presumably this could make the resistant strain adults less damaging in a store, in suitable low stress conditions. However, the diverse stress conditions (moisture, temperature, quinone levels, pathogens, etc) in a grain store environment needs to be considered. This shorter lifespan may not translate to decreased reproduction over generations but the susceptible strain has been replaced universally in grain stores by the malathion resistant strain in spite of this (Beeman and Nanis, 1986; Arnaud et al, 2005; Attia et al, 2020). Previous research on similar T. castaneum strains showed egg hatch percentages and larval weights were significantly lower in the malathion-resistant strain compared to the susceptible strain but on less suitable rice flour the malathion-resistant strain laid more eggs than the susceptible (Bughio and Wilkins, 2004). Fitness benefits of the resistance in this strain become apparent when stressed, which stress is not insecticidal, but not in an unstressed environment.

In a comparison of phosphine susceptible and resistant $T$. castaneum genes associated with the mitochondria had elevated expression in resistant insects (Oppert et al., 2015) but phosphine resistance is usually not stable (Djihinto et al., 2013). Similar shorter lifespans have been found for an artificially enhanced permethrin resistant strain of Anopheles gambiae, which had a knockdown resistance (kdr) mutation and enhanced levels of P450 and esterase enzyme activities. This shows that 
lifespan effects are not limited by the nature of the insecticide, including resistance mechanisms (Otali et al, 2014).

The malathion-resistant strains of $T$. castaneum have exhibited fitness advantages in the absence of insecticide (Haubruge and Arnaud, 2001, Arnaud and Haubruge, 2002, Bughio and Wilkins, 2004, Arnaud et al, 2005), whereas, the majority of fitness trials (which usually exclude adult lifespan) have shown that there are fitness costs associated with other insecticide resistant species. The proportion of fitness cost resistance is $60 \%$ of published research (Freeman et al, 2020). Malathion-resistant strains of stored-product insects often show no reduced fitness compared to susceptible in the absence of any selection pressure (White and Bell 1995, Mason 1998, Guedes et al, 2017).

As mentioned previously that some malathion-resistant $T$. castaneum strains expressed fitness advantages in the absence of malathion (ffrench-Constant and Bass, 2017; Steinbach et al, 2017). However, life span had not been assessed as a component of these fitness studies and the enhanced fitness in the malathion specific strain was due to improved fecundity and reproductive potential (Arnaud et al., 2002). This is an important area as the mechanisms for fitness costs provide the basics of economic optimal models of insecticide resistance management (Brown et al., 2013).

Oxygen, as a highly oxidizing molecule, generates free radicals mainly via the mitochondria (Otali et al., 2014), which then participate in other oxidative chemical reactions (Finkel and Holbrook, 2000; Abele, 2002; Harrison et al., 2006) that are directly correlated with degenerative processes, illnesses and mortality (Skulachev, 2002; Cheng et al., 2003). We have noticed a significant reduction in adult lifespan, in an oxygen atmosphere, of both malathion resistant and susceptible strains of $T$. castaneum which confirms the above findings (Calderon et al, 1991) as well as the relationship with age (Lee and Ducoff, 1983). Sohal et al (1993) reported that raising houseflies in an atmosphere of $100 \%$ oxygen reduced their mean and maximum life span and it increased their levels of protein carbonyls in whole body extracts. Generating $90 \%$ oxygen resistant Drosophila melanogaster by selection over 13 generations lead to gene upregulation and increased body weight (Zhao et al., 2010). A similar response in evolved increased body size was also seen by Klok et al (2009). These fly strains were not assessed for any insecticide resistance. We also have found that the resistant strain $\mathrm{Ph}-10$ was better able to endure oxidative stress and lived significantly longer, in 100\% oxygen environment, than the susceptible FSS-II. Moreover, during oxidative stress conditions, the percent survival, of both late larval and pupal stages to adulthood of the malathion-specific resistant strain, was higher than the susceptible strain. Further oxidative stress was caused by starving the insects and this was related to a reduction in the lifespans, again less in the resistant strain. Fitness was reduced 
by both stressors and this has been confirmed by transcriptome analysis in T. castaneum (Koch and Guillaume, 2020). A related result has been shown with $1 \%$ lyophilized broccoli, included in the food, which significantly elongated the life span of the (not resistant) red flour beetle (T. castaneum) under physiological conditions $\left(32^{\circ} \mathrm{C}\right)$ and under heat stress $\left(42^{\circ} \mathrm{C}\right)$ (Grunwald et al, 2013). Similarly, T. castaneum adults when stressed by heat had extended survival with grape seed extract in their diet (Grunwald et al, 2014). Surprisingly, food grade antioxidants were harmful to T. castaneum when mixed with food; however, the diet was peanut kernels (Garcia et al, 2017).

\subsection{The endogenous antioxidant enzyme, catalase, and its responses to oxidative stressors in the strains of $T$. castaneum}

It is known that most insecticides, including malathion, produce oxidative stress in tissues through the formation of reactive species (ROS) (Abdollahi et al., 2004; Possamai et al., 2007; Guedes et al, 2016; Martelli et al, 2020). The basis of organophosphate toxicity in the production of oxidative stress may be due either to (a) their "redox-cycling" activity, where they readily accept an electron to form free radicals and then transfer them to oxygen to generate superoxide anions and hence hydrogen peroxide through dismutation reactions, or (b) to ROS generation via changes in normal antioxidant homeostasis resulting in antioxidant depletion, if the requirement of continuous antioxidants is not maintained (Kovacic 2003; Yonar 2013).

The unstressed catalase levels in the two strains did not differ significantly. This is in line with Awan et al, (2012) who found no differences between deltamethrin-resistant and susceptible strains of T. castaneum. However, in the mosquito Anopheles funestus, resistant strains (to permethrin) had significantly higher catalase activities than susceptibles (Oliver and Brooke, 2016). When treated with the catalase synergist 3-amino-1, 2, 4-triazole (ATZ) there was significant increase in mortality using deltamethrin (Oliver and Brooke, 2016).

In our study we tested the effect of pure oxygen on the mortality of malathion-specific resistant and susceptible strains of $T$. castaneum treated with malathion, and subsequent in vitro changes in the key antioxidant enzyme catalase. We found a significant increase in mortality of the susceptible strain as compared to the resistant, under the $100 \%$ oxygen conditions which suggests that there might be an additional mechanism in the resistant strain to combat the oxidative stress, along with the confirmed carboxylesterase malathion-specific resistance mechanism (Kodrik et al, 2015; Oliver and Brooke, 2016)

Although there was no significant difference in the catalase activity between the strains, in the air control, there was an induction in the enzyme activity in the resistant strain, after treatment with malathion, with oxygen treatment or after the combined effect of malathion and oxygen, while no 
significant effect of the treatments was noted in the susceptible strain. Based on the known weight of adult $T$. castaneum of these strains (Bughio and Wilkins, 2021) of $2.3 \mathrm{mg}$ (Ph-10) and $2.2 \mathrm{mg}$ (FSS-II) the dosages of malathion applied can be calculated as $70430 \mu \mathrm{g} \mathrm{g}^{-1}$ (Ph-10) and $12.27 \mu \mathrm{g} \mathrm{g}^{-1}$ (FSS-II) (to achieve $\mathrm{LD}_{50}$, assuming complete penetration of cuticle). However, these concentrations will be substantially proportionally reduced at $24 \mathrm{~h}$ when catalase activity was determined. Although the total esterase activity in the resistant was lower than in the susceptible strain the specific malathionase in vivo was much higher ( 7.74 vs. 0.32 pmole/min) and was 28 times higher in vitro (see supplementary material). Thus, remaining malathion could have been below the concentration needed in both strains to elicit significant increases in catalase activity, although there were non-significant increases (whether active/inactive metabolites provide stress is not known). Using Galleria mellonella (single susceptible strain) and sublethal injected doses of imidacloprid a dose-response induction of catalase was found (Yucela and Kayis, 2019). At the lower doses there were no significant increases in catalase activity for up to $96 \mathrm{~h}$ post-treatment. Imidacloprid is likely more persistent in insect tissue than malathion (based on environmental data) but both insecticides induce catalase and other antioxidant enzymes (Yucela and Kayis, 2019.

We found the main difference between the strains was that the resistant strain could induce catalase activity in response to stress (either from malathion or $\mathrm{O}_{2}$ ) and induction increased with both stressors together (Fig 5), whilst the susceptible strain could not, and it also had a lower baseline level.

The increase in this antioxidant enzyme, in both insect strains, was probably a response towards increased ROS generation in organophosphate toxicity. Klichko et al. (2004) found an enhanced activity of catalase, in Drosophila strains, after exposure to $100 \%$ oxygen. DDT and malathion resistant individuals of two Anopheles species showed an increased capacity for coping with oxidative stress, by increasing glutathione peroxidase and catalase activity (Oliver and Brooke, 2016). The small catalase response in our study to either malathion or oxygen alone may be a result of insufficient stressor concentration within the insect body (when assayed). The above studies used stressors in the diet, or for long periods which exerted strong antioxidant responses. Our use of precise topical insecticide treatment provided a method to understand the dose-response relationship in induction of insect defence mechanisms. Further work is needed to explore the relationship in resistant strains.

The current results contradict those of Price et al. (1982) who reported reduced catalase activity, after phosphine treatment, in the resistant and susceptible strains of Rhyzopertha dominica but there was significantly less inhibition in the resistant strain as compared, while all the reference resistant 
strains exhibited higher enzyme activity than the reference susceptible strain. Catalase activity in the red flour beetle has been positively correlated with the strain resistance level to phosphine (Gao, 2009). In the stored product pest Trogoderma granarium peroxidase and superoxide dismutase levels were higher in the moderately phosphine resistant strains but the activity of catalase was only nonsignificantly increased (Yadav et al, 2020). However, the reductant phosphine probably produces diverse effects compared to organophosphates. Additionally, phosphine inhibits the transcription of the catalase gene in Drosophila melanogaster (Liu et al. 2017). It is known that inhibition of oxidative defences, such as catalase, resulted in increased susceptibility to insecticides in Anopheles arabiensis and An. funestus, indicating that oxidative defence is a vital part of insecticide resistance (Oliver and Brooke, 2016). Mosquitoes, stressed oxidatively with paraquat, become more susceptible to insecticides, in this case permethrin and DDT to which defences depend on the upregulation of the P450 system (Champion and Xu, 2018). This in turn depends on availability of catalase (Champion and $\mathrm{Xu}, 2018)$. Longevity in adult D. melanogaster has been associated with overexpression of $\mathrm{Cu}-\mathrm{Zn}$ superoxide dismutase and catalase levels (Orr and Sohal, 1994).

Insecticide, including malathion, poisoning in higher animals, causing free radical damage is an important direct or indirect factor in several pathological and toxicological processes (Possamai et al, 2007). In contrast to our results, Vettraino et al. (2001) reported an extended longevity and a lower level of antioxidant enzyme activity in the paraquat resistant strain of Drosophila suggesting a qualitative change in the enzyme system which contributed towards the resistance against paraquat in the selected strain. Similarly, catalase activity was significantly higher (62\%) in susceptible Sitophilus granarius compared to a phosphine-resistant strain (Bolter and Willian 1990).

\subsection{Oxidative stress through infection}

Our results appear to suggest that the malathion-specific resistant strain has a distinctive ability to survive against Paranosema whitei, a severe obligate pathogen of this insect species. It is reported that this parasite results in almost certain death of the infected populations of T. castaneum. (Blaser and Schmid-Hempel, 2005).

Defence in insects against infections and parasites is mediated through ROS, which are essential components in the immune system (Goswamy and Elrazoqui, 2021). Bacteria such as Wolbachia can affect ROS levels in the host (Zug and Hammerstein, 2015). As a pathogen it can precipitate an immune response and cause oxidative stress, whereas in coevolved symbioses, the relationship promotes redox homeostasis. It is known that insecticide stress impacts various immune mechanisms (James and Xu, 2012). It has been shown that in Drosophila an extracellular immuneregulated catalase (IRC) mediates a key host defence system that is needed during host-microbe 
interaction in the gastrointestinal tract. Strikingly, adult flies with severely reduced IRC expression show high mortality rates even after simple ingestion of microbe-contaminated foods (Ha et al., 2005).

Most fitness studies on insecticide resistance and pathogen stress have used mosquitoes, as their role in vectoring human disease pathogens can be crucial. In the mosquito, Culex pipiens, organophosphate resistant individuals had a greater load of bacteria Wolbachia than the susceptibles, showing a greater fitness cost (Berticat et al, 2002). In a mosquito (Culex quinquefasciatus) with high level of an esterase resistance mechanism the transmission of filariasis was strongly reduced (McCarroll and Hemingway, 2002). In Anopheles gambiae Plasmodium reduced survival in the insecticide resistant strains but not in a susceptible and there was an increase in fecundity for all strains (Alout et al, 2016). Resistance may have changed the interaction between plasmodium and the mosquito, resulting in increased fitness cost of infection. Research on Culex pipiens and the obligate parasite Vavraia culicis, which kills its host before adult eclosion compared organophosphate resistant and susceptible strains (Agnew et al, 2004). The parasite did not affect survival of the susceptible but $40 \%$ of a resistant strain died. The mechanism of resistance in this strain was enhanced esterases (Agnew et al, 2004). This is the reverse of our results; however, the resistance mechanism here was specific malathionase (general esterases did not contribute) and this may not cause ROS production, compared to general esterases. Additionally, the resistant $T$. castaneum had high fitness whereas most of the lifecycle parameters for the resistant $C$. pipiens strain were reduced (Agnew et al, 2004). In deltamethrin-resistant Aedes albopictus there was a fitness cost but a decrease in its competence as a vector. However, the resistant strain still could complete the period of incubation (Deng et al, 2021). Evidence for a link between innate immunity, ROS production and insecticide (including malathion) resistance in Aedes aegypti involving Nrf2 signalling has been found (Bottino-Rojas et al, 2018).

A review in this area (Minetti et al, 2020) reports varied effects on Plasmodium survival according to mosquito species and resistance mechanism. These authors note that "lack of research on this topic is surprising, given the critical impact that any interactions may have on the epidemiology of malaria in an era of widespread pyrethroid resistance". Similar sentiments could be expressed in relation to pest management in stored products where malathion resistance is prevalent. Immunity is carried forward through the beetle's stages (Critchlow et al, 2019) but in assessing the extent of the immunity (adaptive) no account was taken of the insecticide resistance of the population used or the grain species in the store. In this case, (Critchlow et al, 2019), beetles were sampled from a store in 2013, and it is possible that malathion resistance was still extant. Results could have been influenced by this; only by comparison with a truly susceptible strain could it be assessed. 
Insect responses to infection are partly mediated through ROS generated by the NOX/DUOX pathway in the gut (Kim and Lee, 2014). Immune-regulated catalase protects the gut tissue from the action of ROS (Chaitanya et al, 2016). High ROS levels resulting from overexpression of Duox can disrupt cellular function and structure; in T. castaneum up regulation following toxic exposure led to increased antioxidant enzymes (Gao et al, 2020). This type of redox interaction may explain the augmented levels of catalase seen in the current (unstressed) malathion-resistant strain. Immune responses in T. castaneum exposed to $P$. whitei (Lopez-Ezquerra et al, 2018) included gene upregulation involving non-ROS changes, but the authors considered this ROS generation a possibility.

It could be considered that the malathion-resistant strain $\mathrm{Ph}-5$ is itself resistant to $P$. whitei, unlike the susceptible strain. In this case, it would have achieved immunity without having previous exposure to the pathogen, that is without immunity priming. For T. castaneum this has been shown in the case of infection with Bacillus thuringiensis, but with selecting for resistance over 11 generations (Khan et al, 2017). In the current case innate immunity rather than adaptive immunity is likely, although the distinction between the two may not be clear (Criscitiello and de Figueiredo, 2013). In formulating what the relationship between insecticide resistance and immunity to a parasite might be, it may be just the properties of the strains selected here. Further work is needed to extend the implications to other strains of $T$. castaneum and of course other species with stable rersistance, but there has been some support from mosquitoes with another parasite type (McCarroll and Hemingway, 2002). In Myzus persicae with multiple resistance mechanisms there was no fitness cost in reproduction or susceptibility to a pathogen (Erdos et al, 2021). Thus, the pathogen control method would be compatible with insecticides, but would not be so in our case with resistant $T$. castaneum and P. whitei.

GST plays a major role in detoxification and in insecticide resistance, but has been shown not to be a factor in the resistant strain Ph-10. Transcriptome analysis of a susceptible strain of $T$. castaneum comparing it with RNAi treated larvae for blocking GST activity was made (Chen et al, 2016). This also suppressed genes encoding antioxidant enzymes, such as CuZnSOD, Duox, Prx, HPX, CPO, and MCORP. The authors further suggested that these influence the gene's function on lifespan, immunity, development and reproduction. Although this work did not use a resistant strain of T. castaneum it may provide some insight in how resistance to insecticides, and possibly foodstuffs, may interact with immunity to parasites. Injury to adult $T$. castaneum induced the expression of genes for stress adaptation and insecticide resistance; thus, there may be crosstalk between immune and stress responses (Altincicek et al, 2008). 
Resistance to pesticides and pathogens is thought to result in fitness costs, based on evolutionary models (Coustau et al, 2000). However, the insecticide-resistant strain of $T$. castaneum used in our studies had no or little, fitness costs considering responses to the parasite. Potential mechanisms of resistance to pathogens have been suggested (Coustau et al, 2000), but it is unclear how any of these could be related to the known malathion-resistance mechanisms (Coustau et al, 2000). The changes in ROS (including $\mathrm{H}_{2} \mathrm{O}_{2}$ ) could point to a common feature of both stressor types. Unfortunately, measurement of catalase in our T. castaneum strains exposed to P. whitei was not possible due to the low survival of the susceptible strain.

This is the first report on immunity in an insecticide resistant Tribolium sp. and to connect this to catalase activity. In this case, the strain has an uncommon resistance mechanism which involves a specific detoxication pathway. Our results suggest that pure oxygen and malathion exposure provoked oxidative stress and modulated catalase activity in the highly malathion-specific strain of $T$. castaneum, and an induction of a major antioxidant enzyme could have helped the strain to withstand both insecticidal and oxidative stresses. The results would seem to suggest that adaptation to toxic stress such as exposure to insecticides implies some changes other than the usual mechanisms (reduced uptake, modified target, enhanced metabolism) and these can induce major antioxidant enzymes that could have helped the strain to withstand both insecticidal and oxidative stresses.

\section{References}

Abdollahi M, Ranjbar A, Shadnia S, Nikfar S, Rezaie A. Pesticides and oxidative stress: a review. Med Sci Monit. 2004;10:RA141-7. Epub 2004 Jun 1. PMID: 15173684.

Abele, D. 2002. The radical live-giver. Nature 420: 27. doi: 10.1038/420027a.

Agnew P, Berticat C, Bedhomme S, Sidobre C, Michalakis Y, Parasitism Increases and Decreases the Costs of Insecticide Resistance. In Mosquitoes. Evolution, 58(3), 2004, pp. 579-586 x

https://www.jstor.org/stable/3449250

Alout, H., Dabiré, R., Djogbénou, L. et al. Interactive cost of Plasmodium infection and insecticide resistance in the malaria vector Anopheles gambiae. Sci Rep 6, 29755 (2016).

https://doi.org/10.1038/srep29755

Altincicek B, Knorr E, Vilcinskas A, Beetle immunity: Identification of immune-inducible genes from the model insect Tribolium castaneum. Develop Comp Immunol 32, 2008, 585-595.

https://doi.org/10.1016/j.dci.2007.09.005 
Anusree, RP, Pathrose, B, \& Chellappan, M (2020). Malathion resistance in red flour beetle (Tribolium castaneum) (Herbst) (Coleoptera: Tenebrionidae) from FCI godowns of Kerala, India. J Trop Agric, 57. Corpus ID: 216374650

Arnaud, L., and E. Haubruge. 2002. Insecticide resistance enhances male reproductive success in a beetle. Evolution 56: 2435-2444. DOI: 10.1111/j.0014-3820.2002.tb00169.x

Arnaud, L., Y. Brostaux, L. K. Assie, C. Gaspar, and E. Haubruge. 2002. Increased fecundity of malathion-specific resistant beetles in absence of insecticide pressure. Heredity 89: 425-429. doi.org/10.1038/sj.hdy.6800167

Arnaud, L., E. Haubruge, and M. J. G. Gage. 2005. The malathion-specific resistance gene confers a sperm competitive advantage in Tribolium castaneum. Functional Ecology 19: 1032-1039. doi.org/10.1111/j.1365-2435.2005.01055.x

Attia, MA, Wahba, TF, Shaarawy, N, Moustafa, FI, Guedes, RNC, Dewer, Y, 2020. Stored grain pest prevalence and insecticide resistance in Egyptian populations of the red flour beetle Tribolium castaneum (Herbst) and the rice weevil Sitophilus oryzae (L.). J. Stored Prod. Res. 87, 101611. https://doi.org/10.1016/j.jspr.2020.101611.

Awan, D A et al. "Toxicological and biochemical studies on spinosad and synergism with piperonyl butoxide in susceptible and resistant strains of Tribolium castaneum." Pakistan Journal of Zoology 44 (2012): 649-662. Corpus ID: 85816818

Bagchi D, Bagchi M, Hassoun EA, Stohs SJ. In vitro and in vivo generation of reactive oxygen species, DNA damage and lactate dehydrogenase leakage by selected pesticides. Toxicology. 1995;104:129-40. doi: 10.1016/0300-483x(95)03156-a.

Baker, J. E., J. A. Fabrick, and K. Y. Zhu. 1998. Characterization of esterases in malathion-resistant and susceptible strains of the pteromalid parasitoid Anisopteromalus calandrae. Insect Biochem Molec Biol 28: 1039-1050. https://doi.org/10.1016/S0965-1748(98)00095-2

Beeman RW, and Nanis SM, 1986. Malathion resistance alleles and their fitness in the red flour beetle (Coleoptera: Tenebrionidae). J Econ Entomol 79: 580-587. doi.org/10.1093/jee/79.3.580

Beeman, R. W., and B. A. Schmidt. 1982. Biochemical and genetic aspects of malathion-specific resistance in the Indian meal moth (Lepidoptera: Pyralidae) J Econ Entomol 75: 945-949. https://doi.org/10.1093/jee/75.6.945

Berticat C, Boquien G, Raymond M, Chevillon C.. Insecticide resistance genes induce a mating competition cost in Culex pipiens mosquitoes. Genet Res 79: 41-47. 2002. 
Blaser, M., and P. Schmid-Hempel. 2005. Determinants of virulence for the parasite Nosema whitei in its host Tribolium castaneum. J Invert Pathol 89: 251-257. doi: 10.1016/j.jip.2005.04.004

Bolter C, Willina C, 1990. The effect of phosphine treatment on superoxide dismutase, catalase and peroxidase in the granary weevil, Sitophilus granarius. Pestic Biochem Physiol 36:52-60.

Doi:10.1016/0048-3575(90)90020-3

Bonilla, E., S. Medina-Leendertz, and S. Diaz. 2002. Extension of life span and stress resistance of Drosophila melanogaster by long-term supplementation with malathion. Exp. Gerontol. 37: 629-638. doi: 10.1016/s0531-5565(01)00229-7.

Bottino-Rojas V, Talyuli OAC, Carrara L, et al, The redox-sensing gene Nrf2 affects intestinal homeostasis, insecticide resistance, and Zika virus susceptibility in the mosquito Aedes aegypti. J Biol Chem 293, 2018, 9053-9063. DOI 10.1074/jbc.RA117.001589

Bradford, M. M. 1976. A rapid and sensitive method for the quantification of microgram quantities of protein utilizing the principle of protein-dye binding. Anal Biochem 72: 248. doi.org/10.1016/00032697(76)90527-3

Brown ZS, Dickinson KL, Kramer RA. Insecticide resistance and malaria vector control: the importance of fitness cost mechanisms in determining economically optimal control trajectories. $\mathbf{J}$ Econ Entom 2013; 106:366-374. doi: 10.1603/ec11365.

Bughio, F. M., and R. M. Wilkins. 2004. Influence of malathion resistance status on survival and growth of Tribolium castaneum (Coleoptera: Tenebrionidae), when fed on flour from insect-resistant and susceptible grain rice cultivars. J Stored Prod Res 40: 65-75. doi.org/10.1016/S0022474X(02)00077-2

Bughio FM, Wilkins RM, Fitness in a malathion resistant Tribolium castaneum strain; feeding, growth and digestion. J Stored Prods Res 92, 2021, 101814. doi.org/10.1016/j.jspr.2021.101814

Calderon M, Leesch JG, Jay EG, Toxicity of high oxygen atmospheres to Tribolium castaneum (Coleoptera: Tenebrionidae). J Entom Sci (1991) 26: 197-204. doi.org/10.18474/07498004-26.1.197

Cao, G., Feng, H., Guo, F. et al. Quantitative Analysis of Fitness Costs Associated with the Development of Resistance to the Bt Toxin CrylAc in Helicoverpa armigera. Sci Rep 4, 5629 (2014). https://doi.org/10.1038/srep05629 
Chaitanya RK, Shashank K, Sridevi P, Oxidative Stress in Invertebrate Systems. Free Radicals and Diseases, Edited by Rizwan Ahmad, Intechopen.com, 2016, Ch 3, DOI: 10.5772/64573

Chandel, N. S., and G. R. S. Budinger. 2007. The cellular basis of diverse responses to oxygen. Free Radical Biol Med 42: 165-174. doi: 10.1016/j.freeradbiomed.2006.10.048.

Champion CJ \& Xu JN, Redox state affects fecundity and insecticide susceptibility in Anopheles gambiae. SCieNtifiC Reports (2018) 8:13054 DOI:10.1038/s41598-018-31360-2 x

Chen X., Xiong W., Li C., Gao S., Song X., Wu W., Li B., Comparative RNA-sequencing profiling reveals novel Delta-class glutathione S-transferases relative genes expression patterns in Tribolium castaneum (2016) Gene, 593:13-20. doi.org/10.1016/j.gene.2016.08.013

Cheng, Q., N. Valmas, P. E. B. Reilly, P. J. Collins, R. Kopittke, and P. R. Ebert. 2003.

Caenorhabditis elegans mutants resistant to phosphine toxicity show increased longevity and crossresistance to synergistic action of oxygen. Toxicological Science 73: 60-65. doi: 10.1093/toxsci/kfg049

Criscitiello MF, de Figueiredo P, Fifty shades of immune defense. PLoS Pathog. 2013;9(2):e1003110. doi:10.1371/journal.ppat.1003110

Critchlow JT, Norris A, Tate AT, 2019 The legacy of larval infection on immunological dynamics over metamorphosis. Phil. Trans. R. Soc. B 374: 20190066. http://dx.doi.org/10.1098/rstb.2019.0066

Coustau C, Chevillion C, ffrench-Constant RH, 2000. Resistance to xenobiotics and parasites: can we count the cost? Trends in Ecological Evolution 15: 378-383. doi: 10.1016/s0169-5347(00)01929-7

Deng J, Guo Y, Su X, Liu S, Yang W, Wu Y, et al. (2021) Impact of deltamethrin-resistance in Aedes albopictus on its fitness cost and vector competence. PLoS Negl Trop Dis 15(4): e0009391. https://doi.org/10.1371/journal.pntd.0009391

Djihinto CA, Hougni A, Houngbo EN, Katary A, and Bokonon-Ganta HA, Insecticide resistance, fitness cost and resistance stability. Int J Trop Agric Food Sys, 7:17-29 (2013). ISSN: 1597 - 913X

Durusoy, M., N. Diril, and A. N. Bozcuk. 1995. Age-related activity of catalase in different genotypes of Drosophila melanogaster. Experimental Gerontology 30: 77-86. doi: 10.1016/05315565(94)00033-y

Dyte CE, Blackman DG, The spread of insecticide resistance in Tribolium castaneum (Herbst) (Coleoptera, Tenebrionidae) J Stored Prods Res 6, 1970, 255-261. https://doi.org/10.1016/0022474X(70)90015-9 
Erdos Z, Chandler D, Bass C, Raymond B. Controlling insecticide resistant clones of the aphid, Myzus persicae, using the entomopathogenic fungus Akanthomyces muscarius: fitness cost of resistance under pathogen challenge. Pest Man Sci 2021. https://doi.org/10.1002/ps.6571

Felton GW, Summers CB. Antioxidant systems in insects. Arch Insect Biochem Physiol. 1995;29(2):187-97. doi: 10.1002/arch.940290208.

ffrench-Constant RH and Bass C, Does resistance really carry a fitness cost? Curr Opin Insect Sci 2017, 21:39-46. http://dx.doi.org/10.1016/j.cois.2017.04.011

Finkel, T., and N. J. Holbrook. 2000. Oxidants, oxidative stress and the biology of ageing. Nature 408: 239-247. doi: 10.1038/35041687.

Freeman, J.C., Smith, L.B., Silva, J.J., Fan, Y., Sun, H., Scott, J.G., 2021. Fitness studies of insecticide resistant strains: lessons learned and future directions. Pest Manag. Sci. https://doi.org/10.1002/ps.6306.

Futo M, Armitage SAO and Kurtz J (2016) Microbiota Plays a Role in Oral Immune Priming in Tribolium castaneum. Front. Microbiol. 6:1383. doi: 10.3389/fmicb.2015.01383

Gao X-w, Comparison of specific activity of catalase in the phosphine-resistant and phosphinesusceptible strains of red flour beetle Tribolium castaneum (Herbst) (2009) https://www.semanticscholar.org/paper/COMPARISON-OF-SPECIFIC-ACTIVITY-OFCATALASE-IN-THE-Xi-wu/f6d3eda23778cc4f337417c81bc70fde077506b8\#paper-header Google Scholar

Garcia D, Girardi NS, Passone MA, Nesci A, Etcheverry M. 2017. Harmful Effects on Oryzaephilus surinamensis (L.) and Tribolium castaneum by Food Grade Antioxidants and their Formulations in Peanut Kernel. J Food Chem Nanotechnol 3(3): 86-92. Doi.org/10.17756/jfen.2017-042.

Gladyshev VN. The free radical theory of aging is dead. Long live the damage theory!. Antioxid Redox Signal. 2014;20(4):727-731. doi:10.1089/ars.2013.5228

Goswamy D, EIrazoqui J, A unifying hypothesis on the central role of reactive oxygen species in bacterial pathogenesis and host defense in C. elegans. Current Opinion in Immunology 2021, 68:112. https://doi.org/10.1016/j.coi.2020.08.002 x ??

Grigoraki L, Pipini D, Labbe’ P, Chaskopoulou A, Weill M, Vontas J (2017) Carboxylesterase gene amplifications associated with insecticide resistance in Aedes albopictus: Geographical distribution 
and evolutionary origin. PLoS Negl Trop Dis 11(4): e0005533. doi. org/10.1371/journal.pntd.0005533

Grünwald S, Stellzig J, Adam IV, et al. Longevity in the red flour beetle Tribolium castaneum is enhanced by broccoli and depends on nrf-2, jnk-1 and foxo-1 homologous genes. Genes Nutr. 2013;8(5):439-448. doi:10.1007/s12263-012-0330-6

Grünwald S, Fast A, Müller K, Boll M, Kler A, Bonnländer B, and Wenzel U, Feeding a grape seed extract extends the survival of the red flour beetle Tribolium castaneum under heat stress depending on nrf-2, jnk-1, and foxo-1 homologous genes but independent of catechin monomers. Nutrit Medic 2014, 2(1): 13.

Guedes, R. N. C., Smagghe G., Stark J.D., and Desneux N., 2016. Pesticide-Induced Stress in Arthropod Pests for Optimized Integrated Pest Management Programs. Annu Rev Entomol, 2016.61:43-62. DOI: 10.1146/annurev-ento-010715-023646

Guedes, N. M. P.; Guedes, R. N. C.; Campbell, J. F.; and Throne, James E., Mating behaviour and reproductive output in insecticide-resistant and -susceptible strains of the maize weevil (Sitophilus zeamais) (2017). https://digitalcommons.unl.edu/usdaarsfacpub/1979

Guillem-Amat, A., Ureña, E., López-Errasquín, E. et al. Functional characterization and fitness cost of spinosad-resistant alleles in Ceratitis capitata. J Pest Sci 93, 1043-1058 (2020).

https://doi.org/10.1007/s10340-020-01205-x

Ha EM, Oh CT, Ryu JH, et al. An antioxidant system required for host protection against gut infection in Drosophila. Developmental Cell. 2005 8:125-132. DOI: 10.1016/j.devcel.2004.11.007.

Hani Soliman M and Lints FA, 1982. Influence of preimaginal constant and alternating temperatures on growth rate and longevity of adults of five genotypes in Tribolium castaneum. Mech Ageing Dev 1982 18:19-31.

doi: 10.1016/0047-6374(82)90026-4.

Harrison, J., M. R. Frazier, J. R. Henry, A. Kaiser, C. J. Klok, and B. Rascon. 2006. Responses of terrestrial insects to hypoxia or hyperoxia. Respiratory physiology and Neurobiology 154: 4-17. DOI: $10.1016 /$ j.resp.2006.02.008

Haubruge, E., and L. Arnaud. 2001. Fitness consequences of malathion-specific resistance in red flour beetle (Coleoptera: Tenebrionidae) and selection for resistance in the absence of malathion. J Econ Entomol 94: 552-557. doi.org/10.1603/0022-0493-94.2.552

Haubruge, E., M. Amichot, A. Cuany, J.-B. Berge, and L. Arnaud. 2002. Purification and characterization of a carboxylesterase involved in malathion-specific resistance from Tribolium 
castaneum (Coleoptera: Tenebrionidae). Insect Biochemistry and Molecular Biology 32: 1181-1190. doi.org/10.1016/S0965-1748(02)00054-1

James RR, Xu J, Mechanisms by which pesticides affect insect immunity. J Invert Pathol 109, 2012, 175-182. Doi.org/10.1016/j.jip.2011.12.005

Kavallieratos NG, Andrić G, Pražić Golić M, Nika EP, Skourti A, Kljajić P, Papanikolaou NE. Biological Features and Population Growth of Two Southeastern European Tribolium confusum Jacquelin du Val (Coleoptera: Tenebrionidae) Strains. Insects. 2020; 11(4):218. Insects 2020, 11(4),18. https://doi.org/10.3390/insects11040218

Khan I, Prakash A, Agashe D. 2017 Experimental evolution of insect immune memory versus pathogen resistance. Proc. R. Soc. B 284: 20171583. http://dx.doi.org/10.1098/rspb.2017.1583

Khan, A.R., Selman, B.J. On the mortality of Tribolium castaneum adults treated sublethally as larvae with pirimiphos methyl, Nosema whitei and pirimiphos methyl-Nosema $N$. whitei doses. Entomophaga 33, 377-380 (1988). https://doi.org/10.1007/BF02372628

Kim SH and Lee WJ Role of DUOX in gut inflammation: lessons from Drosophila model of gutmicrobiota interactions. Front Cell Infect Microbiol 2014 3:116. doi:

10.3389/fcimb.2013.00116. eCollection 2014.

Klichko VI, Radyuk SN, and Orr WC, Profiling Catalase Gene Expression in Drosophila melanogaster During Development and Aging. Archives of Insect Biochemistry and Physiology 56:34-50 (2004) DOI: 10.1002/arch.10142

Kliot A and Ghanim M, Fitness costs associated with insecticide resistance. Pest Manag Sci 2012; 68: 1431-1437 DOI 10.1002/ps.3395

Klok, C. J., Hubb, A. J. and Harrison, J. F. 2009. Single and Multigenerational Responses of Body Mass to Atmospheric Oxygen Concentrations in Drosophila melanogaster: Evidence for Roles of Plasticity and Evolution. J Evol Biol 22: 2496-2504. doi/10.1111/j.1420-9101.2009.01866.x/full x $\mathrm{xx}$

Kodrík D, Bednářová A, Zemanová M and Krishnan N, Hormonal Regulation of Response to Oxidative Stress in Insects-An Update Int. J. Mol. Sci. 2015, 16, 25788-25816; doi:10.3390/ijms161025788 x 
Koch EL, Guillaume F (2020) Additive and mostly adaptive plastic responses of gene expression to multiple stress in Tribolium castaneum. PLoS Genet 16(5): e1008768.

https://doi.org/10.1371/journal.pgen.1008768

Kovacic, P. 2003. Mechanisms of organophosphates (nerve gases and pesticides) and antidotes: electron transfer and oxidative stress. Curr. Med. Chem. 10: 2705-2709.

DOI: $10.2174 / 0929867033456314$

Lagisz, M., Port, G., Wolff, K., 2010. Living in a jar: genetic variation and differentiation among laboratory strains of the red flour beetle. J. Appl. Entomol. 135, 682-692.

https://doi.org/10.1111/j.1439-0418.2010.01593.xE

Lee YJ and Ducoff HS, Age and sensitivity to oxygen in the flour beetle, Tribolium confusum. Mechanisms of Ageing and Development, 22 (1983) 97-103. DOI: 10.1016/0047-6374(83)90102-1X

Lennicke $\mathrm{C}$ and Cochemé HM, Redox signalling and ageing: insights from Drosophila. Biochem Soc Trans (2020) 48 367-377. https://doi.org/10.1042/BST20190052 x

Li, Y. M., Y. E. Chan, Y. Huang, and Z. Y. Chen. 2007. Green tea catechins upregulate superoxide dismutase and catalase in fruit flies. Mol. Nutr. 51: 546-554. DOI: 10.1002/mnfr.200600238

Liu, T., Li, L., Li, B. et al. Phosphine inhibits transcription of the catalase gene through the DRE/DREF system in Drosophila melanogaster. Sci Rep 7, 12913 (2017).

https://doi.org/10.1038/s41598-017-13439-4

Lopez-Ezquerra A, Mitschke A, Bornberg-Bauer E, Joop G., Tribolium castaneum gene expression changes after Paranosema whitei infection. J Invertebr Pathol. 2018, 153:92-98. doi:

10.1016/j.jip.2018.02.009

Ludovico P, Burhans WC, Reactive oxygen species, ageing and the hormesis police. FEMS Yeast Res 14 (2014) 33-39. DOI: 10.1111/1567-1364.12070

Martelli F, Zuo Z, Wang J, Wong CO, Karagas NE, Roessner U, Rupasinghe T, Venkatachalam K, Perry T, Bellen HJ, Batterham P, Low doses of the neonicotinoid insecticide imidacloprid induce ROS triggering neurological and metabolic impairments in Drosophila. Proceedings of the National Academy of Sciences Oct 2020, 117 (41) 25840-25850; DOI: 10.1073/pnas.2011828117 x 
Mason, P. L. 1998. Selection for and against resistance to insecticides in the absence of insecticide: a case study of malathion resistance in saw-toothed grain beetle, Oryzaephilus surinamensis (Coleoptera: Silvanidae). Bull Entom Res 88: 177-188. https://doi.org/10.1017/S0007485300025748

McCarroll L, Hemingway J, Can insecticide resistance status affect parasite transmission in mosquitoes? Insect Biochemistry and Molecular Biology 32, 2002, 1345-1351.

doi.org/10.1016/S0965-1748(02)00097-8

McKenzie, JA and Farrell KO. 1993. Modification of developmental instability and fitness: malathion-resistance in the Australian sheep blowfly, Lucilia cuprina. Genetica 89: 67-76. DOI: 10.1007/978-94-011-0830-0_7

Milner, R. J., Nosema whitei, a microsporidan pathogen of some species of Tribolium. Entomophaga 18 (2006): 305-315.

DOI 10.1007/BF02371478 Corpus ID: 32328278

Minetti C, Ingham VA, Ranson H, Effects of insecticide resistance and exposure on Plasmodium development in Anopheles mosquitoes. Current Opinion in Insect Science 39, 2020, 42-49. doi.org/10.1016/j.cois.2019.12.001

Nayak MJ, Daglish GJ, Phillips TW, Ebert PR, Resistance to the fumigant phosphine and its management in insect pests of stored products: A global perspective. Annu Rev Entomol 65:333-350 (2020). doi: 10.1146/annurev-ento-011019-025047.

Okoye PN, Brooke BD, Hunt RH, Coetzee M. Relative developmental and reproductive fitness associated with pyrethroid resistance in the major southern African malaria vector, Anopheles funestus. Bull Entomol Res. 2007 Dec;97(6):599-605. doi: 10.1017/S0007485307005317.

Oliver SV, Brooke BD (2016) The Role of Oxidative Stress in the Longevity and Insecticide Resistance Phenotype of the Major Malaria Vectors Anopheles arabiensis and Anopheles funestus. PLoS ONE 11(3): e0151049. doi:10.1371/journal. pone.0151049 x

Oppert B et al., Genes related to mitochondrial functions are differentially expressed in phosphine resistant and -susceptible Tribolium castaneum. BMC Genomics (2015) 16:968 DOI 10.1186/s12864015-2121-0 x

Orr, W. C., and R. S. Sohal. 1994. Extension of life-span by overexpression of superoxide dismutase and catalase in Drosophila melanogaster. Science 263: 1128-1130. doi: 10.1126/science.8108730 xx 
Otali D, Novak RJ, Wan W, Bu S, Moellering DR and De Luca M, Increased production of mitochondrial reactive oxygen species and reduced adult life span in an insecticide-resistant strain of Anopheles gambiae. Bull Entomol Res (2014) 104, 323-333 doi:10.1017/S0007485314000091 x

Parkes, T. L., A. J. Hilliker, and J. P. Phillips. 1999. Motorneurons, reactive oxygen, and life span in Drosophila. Neurobiol. Aging 20: 531-535. doi: 10.1016/s0197-4580(99)00086-x.

Parkin, E. A., E. I. C. Scott, and R. Foster. 1962. Increased resistance of stored-product insects to insecticides. The resistance of field grain Tribolium castaneum. Pest Infestation Research: 34-35.

Possamai FP, Fortunato JJ, Feier G, Agostinho FR, Quevedo J, Wilhelm Filho D, Dal-Pizzol F. Oxidative stress after acute and sub-chronic malathion intoxication in Wistar rats. Environ Toxicol Pharmacol. 2007 23:198-204. doi: 10.1016/j.etap.2006.09.003.

Price, N. R. 1984. Carboxylesterase degradation of malathion in vitro by susceptible and resistant strains of Tribolium castaneum (Coleoptera: Tenebrionidae). Comp Biochem Physiol C Comp Pharmacol Toxicol 1984;77(1):95-8. doi: 10.1016/0742-8413(84)90136-1

Price, N. R., Mills K. A., and Humphries L. A., 1982. Phosphine toxicity and catalase activity in susceptible and resistant strains of the lesser grain borer (Rhyzopertha dominica). Comparative Biochemistry and Physiology 73C: 411-413. doi.org/10.1016/0306-4492(82)90144-7

Rauf, A., Wilkins, R.M., 2002. Expression of a malathion-specific mechanism in a highly resistant strain of Red Flour Beetle Tribolium castaneum Herbst. Proceed Brighton Crop Protect. Conf. 2, 781786.

Rauf, A. and Wilkins RM, Comparative responses of malathion-susceptible and resistant Musca domestica L. strains to oxidative stress. Resistant Pest Management Newsletter 18, 1 (2008) 23-26.

Schieber M, Chandel NS. ROS function in redox signaling and oxidative stress. Curr Biol 2014;24(10):R453-R462. doi:10.1016/j.cub.2014.03.034

Sies H. Oxidative stress: a concept in redox biology and medicine. Redox Biol 4:180-3. 2015. doi: 10.1016/j.redox.2015.01.002.

Sies H. Hydrogen peroxide as a central redox signaling molecule in physiological oxidative stress: Oxidative eustress. Redox Biol 11:613-619. 2017. doi: 10.1016/j.redox.2016.12.035.

Skulachev, V. P. 2002. Programmed death phenomena: From organelle to organisms. Ann. NY. Acad. Sci 951: 214-237. doi: 10.1111/j.1749-6632.2002.tb02095.x 
Sohal, R. S., S. Agarwal, A. Dubey, and W. C. Orr. 1993. Protein oxidative damage is associated with life expectancy of houseflies. Proc. Natl. Acad. Sci. USA 90: 7255-7259. Hyperoxia doi: 10.1073/pnas.90.15.7255

Sokolova YY, Issi IV, Morzhina EV, Tokarev YS, Vossbrinck CR. Ultrastructural analysis supports transferring Nosema whitei Weiser 1953 to the genus Paranosema and creation a new combination, Paranosema whitei. J Invertebr Pathol. 2005; 90:122-6. doi: 10.1016/j.jip.2005.06.009. Epub 2005 Aug 3. PMID: 16083902.

Speakman JR, Blount JD, Bronikowski AM, et al. Oxidative stress and life histories: unresolved issues and current needs. Ecol Evol. 2015;5(24):5745-5757. doi:10.1002/ece3.1790

Spencer, A. G., N. R. Price, and A. Callaghan. 1998. Malathion-specific resistance in a strain of the rust red grain beetle Cryptolestes ferrugineus (Coleoptera : Cucujidae). Bull Entomol Res 88: 199206. https://doi.org/10.1017/S0007485300025761

Steinbach D, Moritza G and Nauen R, Fitness costs and life table parameters of highly insecticideresistant strains of Plutella xylostella (L.) (Lepidoptera: Plutellidae) at different temperatures. Pest Manag Sci 73:1789-1797 (2017). doi.org/10.1002/ps.4597

Suzuki YJ, Forman HJ, Sevanian A. Oxidants as stimulators of signal transduction. Free Radic Biol Med. 1997;22(1-2):269-85. doi: 10.1016/s0891-5849(96)00275-4.

Towarnicki SG, Kok LM, Ballard JWO. Yin and Yang of mitochondrial ROS in Drosophila. J Insect Physiol. 2020 Apr;122:104022. doi: 10.1016/j.jinsphys.2020.104022.

Vettraino J, Buck S, Arking R. Direct selection for paraquat resistance in Drosophila results in a different extended longevity phenotype. J Gerontol A Biol Sci Med Sci. 2001 56:B415-25. doi: 10.1093/gerona/56.10.b415.

Vontas JG, Small JG, and Hemingway J. 2001. Glutathione S-transferases as antioxidant defence agents confer pyrethroid resistance in Nilaparvata lugens. Biochem J 357: 65-72. doi: 10.1042/02646021:3570065

Wang LL, Lu XP, Smagghe G, Meng LW, Wang JJ. Functional characterization of BdB1, a wellconserved carboxylesterase among tephritid fruit flies associated with malathion resistance in Bactrocera dorsalis (Hendel). Comp Biochem Physiol C Toxicol Pharmacol. 2017 200:1-8. doi: 10.1016/j.cbpc.2017.07.001. Epub 2017 Jul 8. PMID: 28697978. 
Wang L, Cui S, Liu Z, Ping Y, Qiu J, Geng X (2018) Inhibition of mitochondrial respiration under hypoxia and increased antioxidant activity after reoxygenation of Tribolium castaneum. PLoS ONE 13(6): e0199056. https://doi.org/10.1371/ journal.pone.0199056 x

White, N. D. G., and Bell R. J, 1995. A malathion resistance gene associated with increased life span of the rusty grain beetle, Cryptolestes ferrugineus (Coleoptera: Cucujidae). J. Gerontol. 50: 9-13. DOI: 10.1093/gerona/50a.1.b9

Whyard S, Russell RJ, Walker VK. Insecticide resistance and malathion carboxylesterase in the sheep blowfly, Lucilia cuprina. Biochem Genet. 1994 Feb;32(1-2):9-24. doi: 10.1007/BF00557235. PMID: 8031296.

Whyard S, Downe AE, Walker VK. Characterization of a novel esterase conferring insecticide resistance in the mosquito Culex tarsalis. Arch Insect Biochem Physiol. 1995;29(4):329-42. doi: 10.1002/arch.940290402. PMID: 7655057.

Yadav, S.K., Srivastava, C., Sabtharishi, S., Phosphine resistance and antioxidant enzyme activity in Trogoderma granarium Everts. J Stored Prod Res 87, 2020, 101636

https://doi.org/10.1016/j.jspr.2020.101636 x

Yamamoto K, Banno Y. Fujii H, Miake F, Kashige N, and Aso Y, 2005. Catalase from silkworm, Bombyx mori: gene sequence, distribution and over expression. Insect Biochem Mol Biol 35: 277283. doi.org/10.1016/j.ibmb.2005.01.001

Yonar SM, Toxic effects of malathion in carp, Cyprinus carpio carpio: Protective role of lycopene Ecotoxicology and Environmental Safety 97, 2013, 223-229. doi.org/10.1016/j.ecoenv.2013.07.020

Yucela MS and Kayis T, Imidacloprid induced alterations in oxidative stress, biochemical, genotoxic, and immunotoxic biomarkers in non-mammalian model organism Galleria mellonella L. (Lepidoptera: Pyralidae). J ENVIR SCI HEALTH, PART B 2019, 54, 27-34. https://doi.org/10.1080/03601234.2018.1530545

Zhao HW, Zhou D, Nizet V, Haddad GG (2010) Experimental Selection for Drosophila Survival in Extremely High O2 Environments. PLoS ONE 5(7): e11701. doi:10.1371/journal.pone.0011701

Zhang XS, Wang T, Lin XW, Denlinger DL, and Xu WH, Reactive oxygen species extend insect life span using components of the insulin-signaling pathway. PNAS 2017114 (37) E7832E7840; doi.org/10.1073/pnas.1711042114 